\title{
ZnO Planar-Tetrapod Synthesized by Cethyltrimethylamonium Hydroxide-Assisted Hydrothermal Method at Low Temperature
}

\author{
Sebastián López-Romero, Manuel García-Hipólito, Mayte Saraí Valverde Labastida, \\ María de Jesús Quiroz Jiménez \\ Instituto de Investigaciones en Materiales, Universidad Nacional Autónoma de México, México DF, México \\ Email: sebas@unam.mx
}

Received 20 June 2015; accepted 24 November 2015; published 27 November 2015

Copyright (C) 2015 by authors and Scientific Research Publishing Inc.

This work is licensed under the Creative Commons Attribution International License (CC BY).

http://creativecommons.org/licenses/by/4.0/

(c) $\underset{\mathrm{EY}}{0}$ Open Access

\begin{abstract}
Planar tetrapods ZnO (PTP-ZnO) or cross shaped tetrapod nanostructures were synthesized by a cethyltrimethylamonium hydroxide (CTAOH)-assisted hydrothermal method at low temperature $\left(120^{\circ} \mathrm{C}\right)$. The XRD diffractogram showed that the PTP-ZnO nanostructures showed a hexagonal wurtzite phase. The studies with high resolution transmission electron microscopy (HRTEM) and select area specific diffraction (SAED) revealed that the $\mathrm{ZnO}$ pods were single crystals and preferentially grew up along [002] direction. The growth mechanism of the CTAOH assisted-hydrothermal synthesized PTP-ZnO nanostructures is explained using the final shape guiding of materials nanostructured and surfactant-action theories.
\end{abstract}

Keywords

ZnO, CTAOH Surfactant Assisted-Hydrothermal Technique, Cross Shaped Tetrapod

\section{Introduction}

Actually, the semiconductor zinc oxide $\mathrm{ZnO}$ is playing a protagonist roll between an oxide metallic family such as $\mathrm{ZrO}_{2}, \mathrm{CaO}, \mathrm{MgO}, \mathrm{SiO}_{2}, \mathrm{Ga}_{2} \mathrm{O}_{3}, \mathrm{In}_{2} \mathrm{O}_{3} \mathrm{TiO}_{2}$ and $\mathrm{SnO}_{2}$ due to its wide band gap (3.2 eV) and large exciton binding energy of $60 \mathrm{meV}$ [1]. With these magnificent properties the $\mathrm{ZnO}$ is strategic in the wide use of basic material for short wave length electro-optically devices such as light emitting diodes and diode laser [2], its large excitation energy can ensure an efficient exciton emission at room temperature and ultraviolet (UV) luminescence has been reported in nanoparticles and thin films [2]-[8]. However, the $\mathrm{ZnO}$ can be used in 
scientific and technological areas including: microelectronic devices [9], chemical and biological sensors [10], light-emitting display [11], catalysis [12] and energy conversion and storage devices [13]. Additionally, ZnO has been synthesized in a great diversity of nanostructures such as nanospring [14], nanorings [15], nanobows [16], nanojunctions arrays [17] [18], nanobelts [14], nanocombs [19], nanopropelles arrays [16] and nanoflowers [20] synthesized efficiently due to the high iconicity of the polar surface [14] [15]. In this work planar tetrapod ZnO (PTP-ZnO) nanostructures were synthesized by a cetiltrimetilamonium hydroxide (CTAOH) assisted-hydrothermal method at $120^{\circ} \mathrm{C}$, and the growth mechanism of the PTP-ZnO was explained using the empirical final shape guiding of materials nanostructured and surfactant-action theories [21]-[23].

\section{Experimental}

\subsection{Preparation of the PTP-ZnO Nanostructures}

The source materials used in this study were analytical reagent grade (Sigma-Aldrich) and used without further purification. Zinc acetate $\left[\mathrm{Zn}\left(\mathrm{CH}_{3} \mathrm{COO}\right)_{2}\right]$ was used as source material of $\mathrm{Zn}$ and cetyltrimethylammonioum hydroxide $(\mathrm{CTAOH})$ as surfactant and catalyst. Initially, $0.01 \mathrm{M}$ of zinc acetate was dissolved in ethyl alcohol and magnetically stirred at $60^{\circ} \mathrm{C}$ for $1 \mathrm{~h}$. Then, cetyltrimethylammonioun hydroxide was mixed into the solution with $\mathrm{Zn} / \mathrm{CTAOH}$ molar ratio of $1 / 1.6$ and then refluxed at $120^{\circ} \mathrm{C}$ for $2 \mathrm{~h}$. It was observed, as a product of the reaction, a white $\mathrm{ZnO}$ powder precipitated at the flask bottom. Then the resulting white powder products were centrifuged, washed with deionized water to remove the organic residues possibly remaining in the final products and finally dried at $60^{\circ} \mathrm{C}$ in air.

The reaction mechanism proposed for hydrothermal synthesis is already reported by J. Zhung and coworkers [17]. In this reaction model is well established that the growth unit corresponds to the anions $\left[\mathrm{Zn}(\mathrm{OH})_{4}\right]^{2-}$. In the context of this model, the following chemical reactions are expected to occur:

$$
\begin{gathered}
2 \mathrm{Zn}\left(\mathrm{CH}_{3} \mathrm{COO}\right)_{2}+4 \mathrm{CH}_{3} \mathrm{CH}_{2} \mathrm{OH} \stackrel{\text { СтаОн- } 120^{\circ} \mathrm{C}}{\longrightarrow} 2 \mathrm{Zn}(\mathrm{OH})_{2}+4 \mathrm{CH}_{3} \mathrm{COOCH}_{2} \mathrm{CH}_{3} \\
\mathrm{Zn}(\mathrm{OH})_{2} \leftrightarrow \mathrm{Zn}^{2+}+2 \mathrm{OH}^{-} \\
\mathrm{Zn}^{2+}+2 \mathrm{OH}^{-} \leftrightarrow \mathrm{ZnO}+\mathrm{H}_{2} \mathrm{O} \\
\mathrm{Zn}(\mathrm{OH})_{2}+2 \mathrm{OH}^{-} \leftrightarrow\left[\mathrm{Zn}(\mathrm{OH})_{4}\right]^{2-}
\end{gathered}
$$

In reaction (1) $\mathrm{Zn}^{2+}$ ions are combined with $\mathrm{OH}^{-}$radicals in the alcoholic solution to form a $\mathrm{Zn}(\mathrm{OH})_{2}$ colloid through the reaction $\mathrm{Zn}^{2+}+2 \mathrm{OH}^{-} \rightarrow \mathrm{Zn}(\mathrm{OH})_{2}$. Later, in the hydrothermal process, the $\mathrm{Zn}(\mathrm{OH})_{2}$ is separated into $\mathrm{Zn}^{2+}$ ions and $\mathrm{OH}^{-}$radicals according to reaction (2). Then, $\mathrm{ZnO}$ nuclei are formed according reaction (3), when the concentration of $\mathrm{Zn}^{2+}$ ions and $\mathrm{OH}^{-}$radicals reaches a super-saturation grade. Finally, the growth unites of $\left[\mathrm{Zn}(\mathrm{OH})_{4}\right]^{2-}$ radicals are obtained through the reaction (4). The dissolution-nucleation cycle according to reactions (5) and (6) respectively produces:

$$
\begin{gathered}
{\left[\mathrm{Zn}(\mathrm{OH})_{4}\right]^{2-} \leftrightarrow \mathrm{Zn}^{2+}+4 \mathrm{OH}^{-}} \\
\mathrm{Zn}^{2+}+2 \mathrm{OH}^{-} \leftrightarrow \mathrm{ZnO}+\mathrm{H}_{2} \mathrm{O} .
\end{gathered}
$$

\subsection{Characterization}

The X-ray diffraction (XRD) pattern of the PTP-ZnO nanostructures was obtained with a X-ray diffractometer

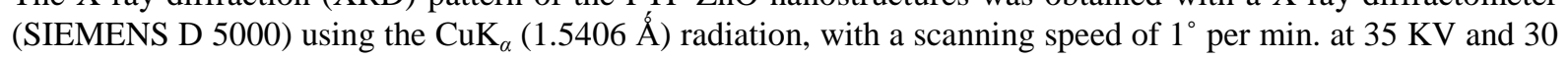
$\mathrm{mA}$. The morphology of the sample was studied using a JEM5600-LV scanning electron microscope. The single-crystal structure of the PTP-ZnO nanostructures was analyzed using a JEOL FEG 2010 Fast TEM electron microscope with a 2.1 Á resolution (point to point).

\section{Results and Discussion}

\subsection{X-Ray Measurements}

Figure 1 shows the XRD pattern of the PTP-ZnO nanostructures synthesized by the CTAOH-assisted hydro- 


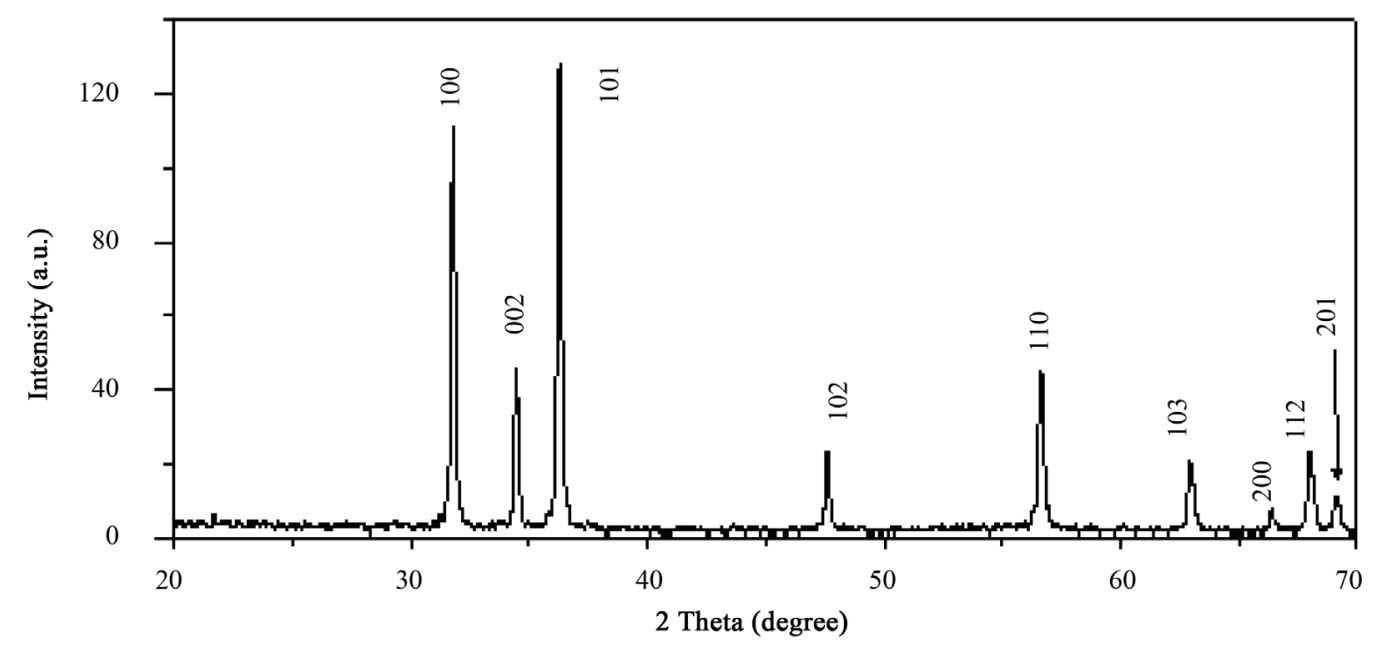

Figure 1. XRD diffractogram of the PTP-ZnO nanostructures.

thermal method at low temperature $\left(120^{\circ} \mathrm{C}\right)$. The XRD diffractograms reveal that this corresponds to $\mathrm{ZnO}$ system with wurtzite structure. All diffraction peaks of the PTP-ZnO nanostructures were indexed to the hexagonal phase of ZnO having lattice parameter a = 3.249 and c = 5.206 ^ (JCPD file No 36-1451).

\subsection{Morphology of the PTP-ZnO Nanostructures}

Figure 2(a) shows the low magnification SEM image of a individual PTP-ZnO sample, it consist of four pods emerging of a common point in four directions at an angle of $90^{\circ}$ between the pods. The wide of the pods ranging between 0.1 and $0.2 \mu \mathrm{m}$, and $7.0 \mu \mathrm{m}$ in length, from this image it can be seen that one end of the pods is pointed. Figure 2(b) shows a panoramic view of many PTP-ZnO nanostructures, it can be observed that all the PTP-ZnO are similar in form with diverse sizes.

Figure 3(a) and Figure 3(b) show the electron diffraction pattern and HRTEM image, respectively, of a pod belonging to a PTP-ZnO nanostructure; Figure 3(a) shows a good crystalline quality of the PTP-ZnO obtained which is consistent with the XRD results shown in Figure 1. The HRTEM image reveals that the interplanar spacing in the crystalline PTP- $\mathrm{ZnO}$ is $0.26 \mathrm{~nm}$ which is the distance between two (002) planes of the $\mathrm{ZnO}$ hexagonal phase indicating the preferential growth along the (002) direction (c axes).

\subsection{Growth Mechanism}

Actually it is possible shape guiding of materials nanostructured by controlling critical parameters in assisted hydrothermal surfactant synthesis technique. Lee [21] showed that the important conditions for selective growth and final shape determination are the following: 1) the crystalline phase of the seed at the nucleating stage of nanocrystals is critical for directing the intrinsic shapes of nanocrystals due to its characteristic unit cell structure; potentially the seeds can have a variety of different crystallographic phases but the stable phase is highly dependent on its environment especially the temperature; 2) the growth time is alternatively a factor that play a important roll in shape control of nanostructures; 3) The delicate balance between the kinetics and thermodynamic growth regimes; in the kinetic regime fast growth on the crystallographic faces with high surface energy promotes 1-D formation. However when sufficient thermal energy is supplied either by utilizing higher growth temperatures $\left(\sim 200^{\circ} \mathrm{C}\right)$ for extended periods of time (i.e. $2 \mathrm{~h}$ at $\left.200^{\circ} \mathrm{C}\right)$ the most thermodynamically stable (spherical shapes) are favored through the intraparticle 1-D to 2-D Oswald Ripening process [22]; 4) organic capping molecules: the surface properties of the nanostructures can be also tailored by the types and the amounts of adsorbing organic capping molecules present in the surfactant or catalyst [23], this capping molecules can affect the intrinsic surface energy of the crystallographic face of the seeds since the kinetic energy barrier is inversely proportional to the surface energy; 5) The molecular precursor which can decompose under mild conditions is critical for kinetics growth process [24].

In the before context on shape guiding of nanostructured materials, in this work PTP-ZnO nanostructures 


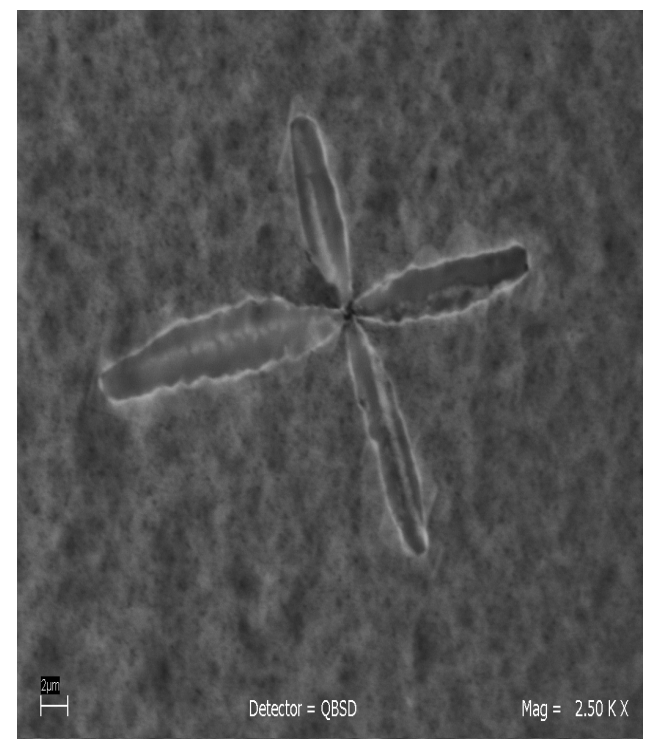

(a)

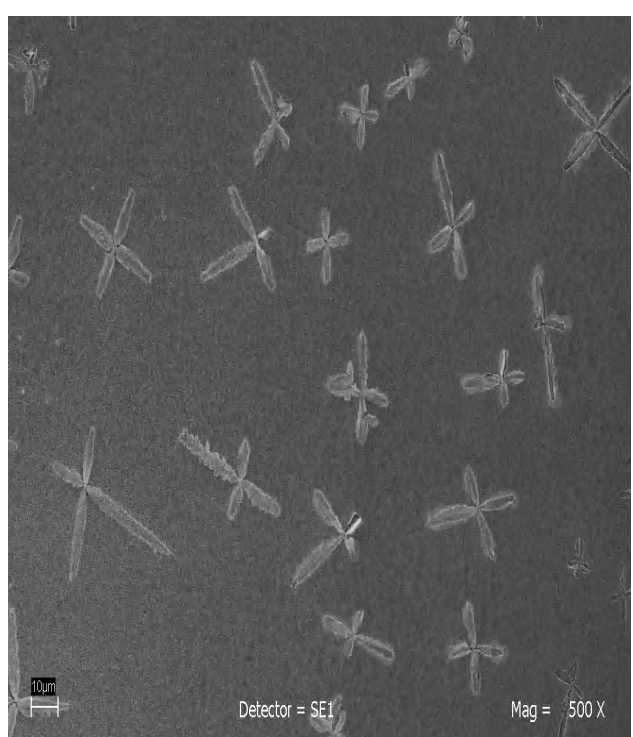

(b)

Figure 2. (a) SEM image of a single PTP-ZnO; (b) panoramic SEM image of many PTP-ZnO nanostructures.
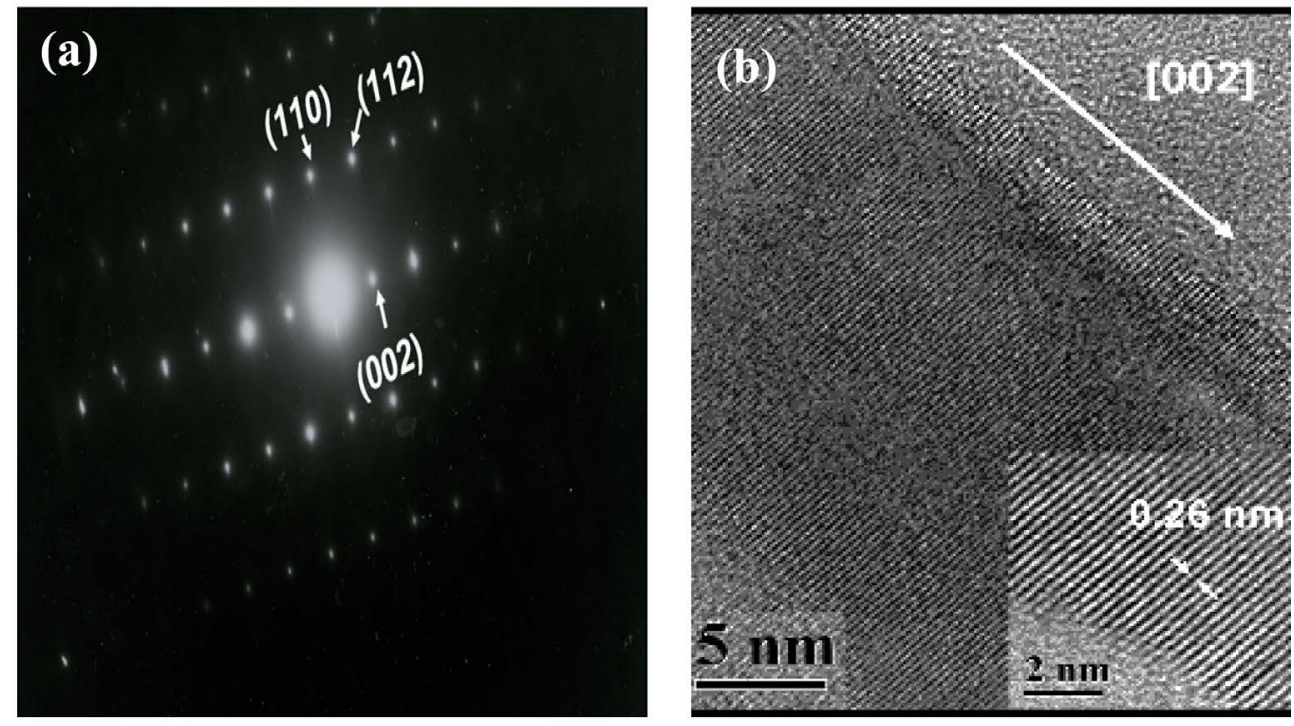

Figure 3. (a) Electron diffraction pattern; (b) HRTEM of an individual pod of a PTP-ZnO.

(cross shaped tetrapod) has been synthesized at $120^{\circ} \mathrm{C}$ by the CTAOH-assisted hydrothermal method taking account as the key parameters in the hydrothermal process the temperature and the capping molecules. Thus in the hydrothermal process to obtain the PTP-ZnO nanostructures at low temperature $\left(120^{\circ} \mathrm{C}\right)$ it is assumed that the seed unit cell formed in the initial nucleation process is an truncated octahedron with faces which have an crystallographic hexagonal wurtzite structure formed in the central region of the cross-like and from them the growth of the $\mathrm{ZnO}$ pods is possible through the preferential growth on the four opposite faces of the $\{100\}$ faces of the truncated octahedron seed. Finally the $\mathrm{ZnO}$ pods are grown along the $\{002\}$ directions (c axes) with interplanar separation distance of $0.26 \mathrm{~nm}$. In other words the phase of the $\mathrm{ZnO}$ pods nanocrystals was determined by the temperature-mediated phase control of the initial seed. However, the played roll of the CTMAOH is as surfactant and catalyst.

Once that an determined crystalline phase has been selected during the initial nucleation stage the delicate balance between the growth kinetic and the thermodynamic growth regimes will affect strongly the final archi- 
tecture of the $\mathrm{ZnO}$ nanocrystals, in our hydrothermal experiment the temperature used was low $\left(120^{\circ} \mathrm{C}\right)$ and in non-equilibrium condition selective anisotropic growth between different crystallographic faces is established: in our case since the surface energy of the (001) face of the wurtzite phase is higher than that other faces, selective growth through the $\mathrm{c}$ axes of the hexagonal $\mathrm{ZnO}$ pod is induced.

To observe the influence of the CTAOH on the hydrothermal process other two experiments were made: one without $\mathrm{CTAOH}$ and second one at higher temperature $\left(200^{\circ} \mathrm{C}\right)$ : in the first experiment only particles of about $100 \mathrm{~nm}$ were obtained see Figure 4 this occurs because there are not active sites on the $\mathrm{ZnO}$ seed surface. Furthermore the growth rate of the $\mathrm{c}$ axis is low because the reaction temperature is low. However due to the presence of the CTAOH surfactant in the hydrothermal process capsules of $\mathrm{CTAOH}$ are generated in saturation condition and due to the coulomb force action between the anion unites $\left[\mathrm{Zn}(\mathrm{OH})_{4}\right]^{2-}$ and the cation capsules surfactants $\mathrm{CTAOH}$ they interact to form complexing agents which are adsorbed on the surface of the $\mathrm{ZnO}$ seed, this adsorption of the complexing agents decreases the surface energy of the $\mathrm{ZnO}$ resulting in the generation of active sites on the $\mathrm{ZnO}$ surface, thus at low temperature condition $\mathrm{ZnO}$ pods with point ends can growth on these active sites. Consequently without the $\mathrm{CTAOH}$ presence in the hydrothermal process only particles can be obtained. In the second experiment at $200^{\circ} \mathrm{C} \mathrm{ZnO}$ nanorods were obtained, Figure 5 is an SEM image of the $\mathrm{ZnO}$

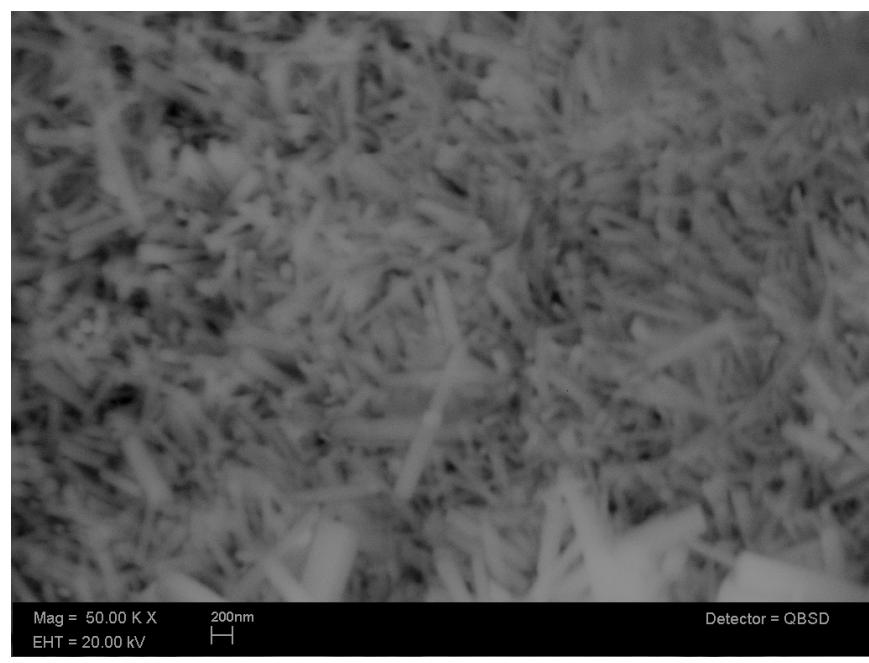

Figure 4. SEM Image of the particles obtained at $120^{\circ} \mathrm{C}$ without the action of the CTAOH.

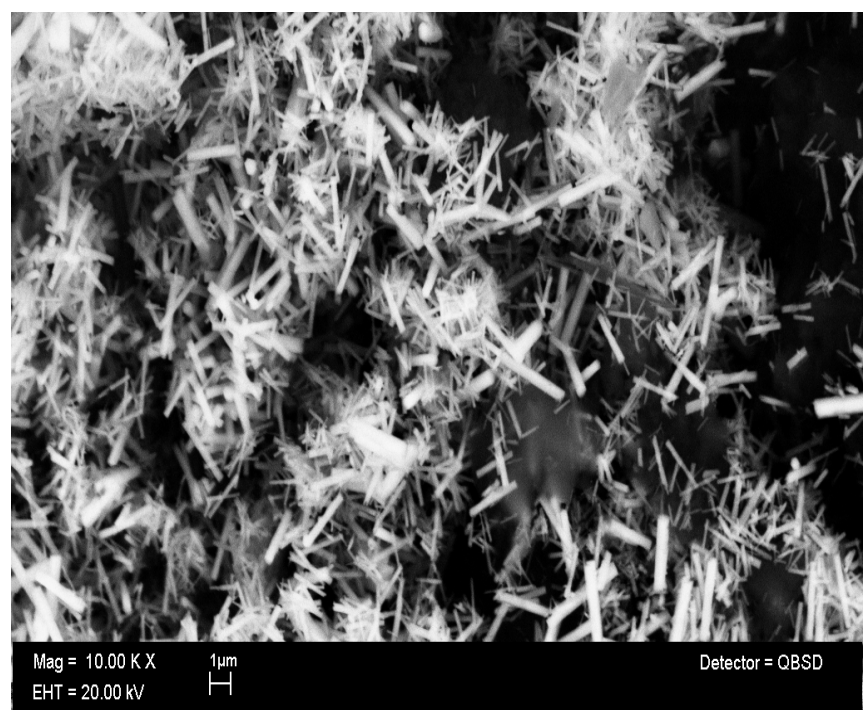

Figure 5. Nanorods obtained at $200^{\circ} \mathrm{C}$ with $\mathrm{CTAOH}$. 
nanostructures thus obtained, it clearly shows that $\mathrm{ZnO}$ nanorods but no PTP-ZnO nanostructures are obtained, this is because the capsules of $\mathrm{CTAOH}$ are normally destroyed at $160^{\circ} \mathrm{C}$ in the hydrothermal process and as a consequence only an individual $\mathrm{CTAOH}$ molecule interact with a growth unit $\left[\mathrm{Zn}(\mathrm{OH})_{4}\right]^{2-}$ to form a complex agent which is adsorbed on the surface of the $\mathrm{ZnO}$ seed an active site will form and $\mathrm{ZnO}$ nanorods preferentially grows in this site.

\section{Conclusion}

In this work planar tetrapod (shaped cross-like nanostructures) of ZnO (PTP-ZnO) were synthesized by the $\mathrm{CTAOH}$-assisted hydrothermal method at $120^{\circ} \mathrm{C}$. The $\mathrm{ZnO}$ phase obtained for the pods belonging to the PTP$\mathrm{ZnO}$ was the wurtzite hexagonal phase; the $\mathrm{ZnO}$ pods crystal single grown along the (002) direction with a separation distance between the (002) faces of $0.26 \mathrm{~nm}$. The total influence of the temperature in the hydrothermal reaction and the initial nuclei seed obtained join with the effect of the capping molecules on the shape of the end architecture for the $\mathrm{ZnO}$ nanostructures confirmed the validity of the empirical theory on guiding shape final of nanostructures in a surfactant-assisted hydrothermal process.

\section{Acknowledgements}

The authors wish to thank to Adriana Tejeda (IIM) for the XRD measurements. To Omar Novelo Peralta (IIM), Carlos Flores (IIM) and Luis Rendón (IF) for their support in the SEM and TEM characterization. The authors are also thankful to the Central Microscopy facilities of the Institute of Physics, UNAM, for providing the microscope tools used in this work.

\section{References}

[1] Wong, E.M. and Searson, P.C. (1999) ZnO Quantum Particles Thin Films Fabricated by Electrophoretic Deposition. Applied Physics Letters, 74, 2939. http://dx.doi.org/10.1063/1.123972

[2] Huang, M.H., et al. (2001) Room Temperature Ultraviolet Nanowire Nanolasers. Science, 292, 1897. http://dx.doi.org/10.1126/science.1060367

[3] Zhan, J., Zun, L.D., Yin, J.L. and So, J.L. (2002) Control of ZnO Morphology via a Simple Solution Route. Chemical of Materials, 14, 4172-4176. http://dx.doi.org/10.1021/cm020077h

[4] Hu, J.Q., Brando, Y., Zhan, J.H. and Sekiguchi, T. (2002) Two-Dimensional Micrometer-Sized Single-Crystalline ZnO Thin Nanoshets. Applied Physics Letter, 83, 4414-4418. http://dx.doi.org/10.1063/1.1629788

[5] Lao, J.Y., Wen, J.G. and Ren, Z.F. (2002) Hierarchical ZnO Nanostructures. Nano Letters, 2, 1287-1291. http://dx.doi.org/10.1021/nl025753t

[6] Gao, P.X. and Wang, Z.L. (2003) Mesoporous Polyhedral Cajes and Shells Formed by Textured Self-Assembly of ZnO Nanocrystals. Journal of American Chemical Society, 125, 11299-11305. http://dx.doi.org/10.1021/ja035569p

[7] Wang, X.D., Sumersan, C.J. and Wang, Z.L. (2004) Large-Scale Hexagonal-Patterned Growth of Aligned ZnO Nanorods for Nano Optoelectronics and Nanosensor Arrays. Nano Letters, 4, 423-426. http://dx.doi.org/10.1021/nl035102c

[8] Gao, P.X., Ding, Y., Mai, W.J., Hughes, W.L., Lao, C.S. and Wang, Z.L. (2005) Conversions of Zinc Oxide Nanobelts into Superlatice-Structured Nanohelices. Science, 309, 1700-1704. http://dx.doi.org/10.1126/science.1116495

[9] Lauhon, L.J., Gudiksen, M.S., Wang, D.L. and Lieber, C.L. (2002) Epitaxial Core Shell and Core Multishells Nanowire Heterostructures. Nature, 420, 57. http://dx.doi.org/10.1038/nature01141

[10] Modi, A., Koratkar, N., Lass, E., Wei, B.Q. and Ajayan, P.M. (2003) Miniaturized Gas Ionization Sensors Using Carbon Nanotubes. Nature, 424, 171-174. http://dx.doi.org/10.1038/nature01777

[11] Banerjee, D., Jo, S.H. and Ren, Z.F. (2004) Enhanced Field Emission of ZnO Nanostructures Grown on Carbon Clot. Advanced Materials, 16, 2028-2032. http://dx.doi.org/10.1002/adma.200400629

[12] Bansal, V., Jani, H., Du Plessis, J., Coloe, E.J. and Bargava, S.K (2008) Galvanic Replacement Reaction on Metal Films: A One-Step Approach to Create Nanoporous Surfaces for Catalisis. Advanced Materials, 20, 717-723. http://dx.doi.org/10.1002/adma.200701297

[13] Arico, A.S., Bruce, P., Serosati, B., Tarascon, J.M. and Van Schalwijk, W. (2004) Nanostructured Materials Advanced for Energy Conversion and Storage Devises. Nature Materials, 4, 366-377. http://dx.doi.org/10.1038/nmat1368

[14] Kong, X.Y. and Wang, Z.L. (2003) Spontaneous Polarization-Induced Nanohelixes, Nanospring, and Nanorings of Piezoelectric Nanobelts. Nano Letters, 3, 1625-1631. http://dx.doi.org/10.1021/nl034463p 
[15] Huang, M.H., Wu, Y., Feich, H., Tran, N., Weber, E. and Yang, R. (2001) Catalytic Growth of Zinc Oxide Nanowires by Vapor Transport. Advanced Materials, 13, 113-116.

http://dx.doi.org/10.1002/1521-4095(200101)13:2<113::AID-ADMA113>3.0.CO;2-H

[16] Hughes, W. and Wang, Z.L. (2004) Formation of Piezoelectric Single-Crystals Nanorings and Nanobows. Journal of the American Chemical Society, 126, 6703-6709. http://dx.doi.org/10.1021/ja049266m

[17] Pan, W., Dai, Z.R. and Wang, Z.L. (2001) Nanobelts of Semiconducting Oxides. Science, 291, 1947-1950. http://dx.doi.org/10.1126/science.1058120

[18] Wang, Z.L., Kong, X.Y. and Zuo, J.M. (2003) Induced Growth of Asymmetric Nanocantilever Arrays on Polar Surface. Physical Review Letter, 91, Article ID: 185502. http://dx.doi.org/10.1103/PhysRevLett.91.185502

[19] Kong, X.Y., Dine, Y., Yang, R. and Lin, Z. (2004) Single-Crystal Nanorings Formed by Epitaxial Self-Coiling of Polar Nanobelts. Science, 303, 1348-1351. http://dx.doi.org/10.1126/science.1092356

[20] Lopez-Romero, S., Santiago, P. and Mendoza, D. (2011) Hydrothermal Synthesis and Characterization Structural of Flower-Like ZnO Nanostructures. Advanced Science Letters, 4, 1-5.

[21] Lee, S.-M., Cho, S.-N. and Cheon, J.W. (2003) Anisotropic Shape Control of Colloidal Inorganic Nanocrystals. Advanced Materials, 15, 441-444. http://dx.doi.org/10.1002/adma.200390102

[22] Baldan, A. (2002) Review Progress in Oswald Ripening Theories and Their Applications to Nikel-Base Superallops. Part 1 Oswald Ripening Theories.

[23] Jun, Y.-W., Jung, Y.-Y. and Cheon, J.W. (2003) Architectural Control of Magnetic Semiconductor Nanocrystals. Journal of American Chemical Society, 124, 615-619. http://dx.doi.org/10.1021/ja016887w

[24] Zhang, Y., Xu, J., Xiang, Q., Li, H., Pan, Q. and Xu, P.H. (2009) Brush-Like Hieratical ZnO Nanostructures: Synthesis, Photoluminescence and Gas Sensor Properties. The Journal of Physical Chemistry C, 113, 3430-3435. http://dx.doi.org/10.1021/jp8092258 